\title{
Ferréz: más allá del documentalismo
}

Lucía Tennina $^{1}$

La literatura brasileña del presente cuenta entre sus nombres más reconocidos nacional e internacionalmente a Ferréz, un escritor proveniente de una favela de la Ciudad de São Paulo que se asocia al término "literatura marginal", acuñado por él mismo, dado que la mayoría de sus textos están localizados en la región donde vive hasta hoy en día (la periferia de la zona Sur de São Paulo) y están colmados de jergas propias de esos barrios.

La historia de las publicaciones de Ferréz da cuenta de la importancia del pasaporte territorial para lograr una visibilidad en sus producciones. Su primer libro, Fortaleza da desilusão, por ejemplo, es un libro de poesía concreta que no hace mención al día a día en los barrios periféricos y no tuvo ninguna repercusión ni en la prensa ni entre sus actuales seguidores (de hecho, no se consigue). Recién con su segunda publicación, Capão pecado, alcanza una visibilidad y una cantidad de lectores que superan en gran medida las de la primera.

De acuerdo con la antropóloga Érica Peçanha do Nascimento, fue recién a partir de la decisión de escribir sobre su "realidad" que los textos de Ferréz ganaron nuevos lectores y visibilidad en los medios de comunicación, no tanto por sus valores literarios sino por la particularidad de quien lo firmaba: "O romance não foi saudado como acontecimento literário, tampouco foi lançado sob o aval de algum crítico renomado, mas movimentou o interesse da imprensa, que buscou evidenciar mais os aspectos sociológicos relacionados à produção do que as características da própria obra" (Nascimento, 2009, p. 43).

No podemos negar que la visibilidad de la producción y figura de Ferréz se debe en gran medida a la operación mediática que se montó producto del interés de las clases medias sobre los discursos sobre las favelas brasileñas. ${ }^{2}$ De todos modos, ¿por qué fue la obra de Ferréz la que

\footnotetext{
${ }^{1}$ Doctora en letras y profesora de la Facultad de Filosofía y Letras da Universidad de Buenos Aires (UBA), Buenos Aires, Argentina. Es becaria posdoctoral del Consejo Nacional de Investigaciones Científicas y Técnicas (Conicet). E-mail: luciatennina@gmail.com

${ }^{2}$ Como señala Heloísa Buarque de Hollanda (2012, p. 277), "Ferréz está en guerra hace un buen tiempo [...]. En esa época también surgía, de forma más explícita, el interés de las clases medias por la intensificación de la violencia y los enfrentamientos policiales que se multiplicaban por las periferias urbanas."
} 
alcanzó gran destaque y no la de otros escritores contemporáneos a Ferréz y con trayectorias similares? En la misma época en que Ferréz publicó dicho libro existían otros escritores de las regiones periféricas de la ciudad de San Pablo que estaban queriendo proyectar una carrera de escritor a partir de textos que diesen cuenta de la vida en sus barrios. Ese mismo año, Alessandro Buzo, por ejemplo, un escritor del extremo este de la misma ciudad, publicaba por sus propios medios $O$ trem: contestando a versão oficial, libro que daba cuenta de las precariedades de un usuario del tren desde el conurbano profundo al centro de la ciudad. Varios años antes, en diciembre de 1988, Sérgio Vaz, un escritor del barrio de Piraporinha, región de Santo Amaro, zona Sur de San Pablo, publicaba en coautoría con Adriane Mucciolo, Subindo a ladeira mora a noite, en una edición pequeña y autosustentada, donde se puede leer una voz esperanzada ante las dificultades del día a día que implicaba vivir en uno de los lugares más violentos del mundo de acuerdo con las estadísticas de la ONU. En 1991, con el apoyo económico de la empresa para la cual trabajaba, ese mismo escritor lanza su segundo libro, A margen do vento, en una edición un poco mayor, cuya difusión estuvo a su cargo y no alcanzó grandes ventas. Hacia mediados de la década de 1990, Binho Padial también había empezado a hacer pública su propia poesía por las calles de su barrio, Campo Limpo, usando como hoja de papel el revés de los carteles de los políticos, que volvía a colgar en su lugar con poesías de protesta mirando hacia el frente. A esta publicación colectiva en su montaje, pero individual en la firma, le puso el título de Postesía. Poesía nos postes y fue publicada por el propio autor en marzo de 1999.

Como podemos ver, la particularidad de Ferréz entre otros escritores de las regiones periféricas de São Paulo de aquella época no pasa solamente por ser una pluma de origen favelado, dado que su producción no es una excepción entre sus pares, ni tampoco por la temática abordada, porque en definitiva lo que cuenta en sus argumentos no es algo que impacte en el lector de la época en que fue publicado, habituado a las películas y programas de televisión que hablan de las favelas (que en ciertas ocasiones llegan a tal extremo que frente a algunas escenas se ven obligados a acompañarlas con la leyenda "Algunas imágenes pueden herir la sensibilidad del espectador").

La hipótesis de este artigo es que la literatura de Ferréz ocupa un lugar central entre las producciones de la literatura brasileña contemporánea no solamente por su temática o la historia de vida de escritor, sino por un 
trabajo dedicado que lleva a cabo ya desde sus primeros textos en relación con desestabilizar y reactualizar la distinción entre ficción y no ficción, por un lado, y una propuesta singular del estatuto de lo real, por otro , colocándose en el centro de las preocupaciones más instigantes de las literaturas del presente. El análisis se centrará en sus dos primeras novelas, la primera edición de Capão pecado (2000) y Manual prático do ódio (2003), que fueron las que proyectaron a este escritor al lugar destacado que ocupa hoy en día.

Según el autor, el nacimiento de su primera novela surgió de la siguiente percepción:

Empecé a escribir un libro que se llama Capão pecado con la idea de que iba a contar simplemente la realidad [...] el libro empezó a hacerse así, sólo que caí en la fuerte verdad de que la realidad no cabe en un libro, no se puede poner la realidad en un libro, así que tuve que adaptar la realidad. Y usé mi don de mentiroso, en el fondo todo escritor es un gran mentiroso, así que tuve que mentir mucho en el libro y cambiar las historias para que queden ficcionalizadas en una sola historia (Ferréz apud Tennina, 2013, p. 124-125, el énfasis es mío).

La producción de Ferréz tendría su punto de partida en una "realidad" que supera su capacidad de ser contada y que, por lo tanto, requiere ser intervenida en tanto mentira y adaptada en tanto ficción. La idea de "adaptar" la realidad (esto es, de alguna manera, editarla) parece corresponderse con el acto de mentir y, a su vez, el acto de mentir se asocia directamente al acto de hacer ficción, es decir que existe un real no editado que se asocia a la verdad y un real editado que se asocia a la mentira. El primer efecto de este vaivén entre "realidad" y "ficción" tiene que ver con la duda constante respecto de qué aspectos tienen un carácter referencial (qué sucedió y qué existe verdaderamente, o sea, en el plano de lo real) y qué aspectos son puramente invenciones del autor (qué de lo que se narra es "mentira"). En otras palabras, esta distinción tiene implicancias en relación con el pacto de lectura que los textos habilitan. La obra de Ferréz, ¿se lee como literatura? ¿Cómo literatura de ficción o de no ficción? ¿Admite una lectura meramente documental?

En la edición original de su primera novela Capão pecado (2000), la inclusión de fotografías juega un papel central en el vaivén entre esas preguntas dado que pueden considerarse como documentos que testimonian o aportan información sobre aquello que se narra. Además 
de 23 capítulos - organizados en cinco partes que abren con un breve texto de diferentes raperos de la zona sur -, el libro contiene dos apartados fotográficos y una fotografía de apertura con un primer plano del autor, en el que asoma su mano haciendo un gesto rapero, y con la favela como fondo.

Estas imágenes, principalmente las del interior del libro, contribuyen a pensar que existe una coincidencia entre ellas y el relato. La primera sospecha es que el protagonista del libro, Rael, remite a Ferréz, dada la cantidad de fotografía del autor en el interior del libro (además de la imagen de apertura, en la sección de fotografías a color, hay otras dos en las que aparece) y los indicios textuales que asocian la imagen de Rael con el autor (entre otros, el hecho de que ambos sean grandes lectores, estén interesados por las historietas y sus madres sean empleadas domésticas). Incluso habría un parecido físico entre ambos: "Seu aspecto sempre agradava as mães dos colegas: gordinho, cabelo todo encaracolado, e um óculos grande e preto que ele já usava há muito tempo" (Ferréz, 2000, p. 26). Finalmente, tanto el escenario del texto como el de las imágenes remiten a barrio de Capão Redondo, donde el autor nació y vive hasta hoy.

La confluencia entre el escenario del relato y el captado en las fotografías lleva al lector a no olvidarse nunca del referente y a actualizar recurrentemente la pregunta respecto del carácter de "verdad" de lo narrado. Ambos insisten en los mismos temas. Por un lado, los problemas de infraestructura. Como señala Sophia Beal, "Capão pecado's photographs show that the public services of the neighborhood are as precarious as the texts suggest" (Beal, 2013, p. 125). Además, ambos presentan e insisten en el mismo tipo de transporte que hace al paisaje de esos barrios, las motos y los "fuscas" (Volkswagen Tipo 1, que en español se conocen como "escarabajos"). Se repiten también las referencias a la presencia de los niños en las calles jugando o pasando el rato, referencias que presentan a la infancia como un locus amoenus que contrasta con la realidad del adulto - construcción que no se sostiene, de todos modos, en la foto de tapa que analizaremos más adelante -. Las fotos y el relato muestran, además, un mundo principalmente masculino puertas afuera. Por último, hay una presencia fuerte del hip hop a través de personajes que aparecen en las fotos y que firman los textos que dan inicio a las partes del libro (como Mano Brown) y a través de las vestimentas con remeras o camisas y pantalones un talle más grande. 
Manual prático do ódio, publicado tres años después (2003) por la editorial Global, también propone un vaivén entre ficción y realidad, aunque de manera diferente. En esta obra - que no incluye fotografías en su interior - lo que desorienta al lector respecto de la coincidencia o no de lo narrado con la "realidad", principalmente, es la contratapa de libro: "Todos os personagens deste livro existem ou existiram mas o Manual prático do ódio é uma ficção". El texto lleva al lector, nuevamente, a la duda constante: de lo que se lee, ¿qué fue efectivamente así y qué es ficción? La dedicatoria en forma de obituario que se encuentra al abrir el libro profundiza esta idea: se puede leer una lista de 35 personas antecedida por la inscripción "Os familiares e amigos choraram por". Una vez concluida la lectura, los lectores son llevados a la duda respecto de quién de esas personas es quién frente a los personajes de la novela.

Pero la producción de Ferréz no se limita a ese vaivén entre "realidad" y "ficción" que puede, efectivamente, llevar a un análisis de su obra en tanto "documentalista" antes que estética (Süssekind, 2005; Schollhammer, 2009). Los textos de Ferréz presentan algo del orden de lo indomable y es ahí donde podemos afirmar que van más allá del documentalismo y entran al universo de la creación, dado que ponen en crisis los límites de lo decible, de lo escuchable y de lo inteligible.

El montaje (la edición) que hace Ferréz para adaptar esa realidad que "no cabe en un libro" deja algunos huecos, algunas grietas que no logran ser absorbidas por el sistema de significación dominante y que dan cuenta de una idea de ficción que suspende cualquier tipo de reduccionismo. En otras palabras, más allá de la propuesta de "ficción" ligada a la "realidad", se percibe en los textos de Ferréz un cierto real no editado que supera el documentalismo y que lleva a sus producciones a una idea de ficción que ya no tiene que ver con la oposición "realidad (verdad) / ficción (mentira)", sino con una idea vinculada a lo indomable o, más precisamente, lo intempestivo, usando un término de Ítalo Moriconi (2006, p. 159): “O real é o que nos traz a imagem bruta, não editada. Existe a imagem editada, predominante no fluxo cotidiano da cultura, e a imagem não editada, que tem um potencial de intempestividade. Nesse sentido, o signo intempestivo hoje mais provavelmente estará do lado do real que do lado da ficção", entendiéndose "ficción", de acuerdo con la lógica de Moriconi en la que resuenan las teorías de Baudrillard (1978) y Zizek (2002), como "produção de simulacro" (p. 160). Siendo que hoy en día en la cultura mediatizada 
todo es ficción, hay algo que escapa a dicho simulacro y que irrumpe intempestivamente en ciertos discursos literarios del presente, afirma Moriconi, y, creemos, la literatura de Ferréz podría formar parte de esa serie. El uso de las fotos que no dialoga con el relato, la aplicación de las jergas de la periferia de São Paulo que lo vuelven muchas veces intraducible, la escritura de párrafos extensos sin puntos y colmados de comas, la construcción de personajes ambiguos y complejos, la superpoblación de personajes secundarios que no se vinculan con la trama principal, son elementos característicos de las novelas de Ferréz que, como veremos, nos orientan hacia una lectura de sus textos en un sentido de desborde que suspende los límites entre "realidad" y "ficción".

Hay un ejemplo muy claro en este sentido en Capão pecado. La trama se centra en la historia de Rael, de su amante y futura mujer Paula, y de sus amigos, entre los cuales está su mejor amigo, Matcherros, en un principio novio oficial de Paula. Aparecen, además, como suele ocurrir en las novelas de Ferréz, muchos personajes secundarios, entre ellos Carimbê, el tío de Matcherros, que hasta el capítulo 14 inclusive solo es mencionado al pasar en dos oportunidades como un borracho perdido, sucio y abyecto, que se la pasa tirado en el sofá del living de la casa de Matcherros: "Tudo era sujeira em sua volta. Sua respiração era lenta e forte, seu olhar concentrado no teto, estava bêbado novamente" (2000, p. 120).

Llamativamente, el capítulo 15 está dedicado por completo a este personaje, por más que no aporte nada a la economía de la historia. El escenario no es el barrio de Capão Redondo, sino Rio de Janeiro y lo narrado transcurre en un tiempo anterior a la trama de la novela. En ese contexto, nos enteramos de muchos detalles de la vida de Carimbê, desde su infancia nordestina y los consejos de sus padres, hasta su adultez como obrero en Rio de Janeiro, donde solía beber y bailar forró hasta que una noche pierde todo lo que tenía como consecuencia de un enfrentamiento con un policía y en una cadena de desgracias, pierde el trabajo y su hogar, viaja a São Paulo para cobrar la indemnización y finalmente se queda a vivir allí, en la casa de su hermana, la madre de Matcherros. El capítulo cierra con la frase "percebe que sua vida, no total, não passa de uma grande decepção" (p. 130). Esa misma frase aparece tres páginas antes como cita debajo de una fotografía en blanco y negro que muestra a un hombre sucio y abandonado, sentado en la puerta de un bar mirando a la nada, con sus muletas apoyadas en la pared (Imagen 15, p. 289). Parece tratarse de un guiño que pretende dar 
a entender que el fotografiado es Carimbê. Luego de este capítulo, la historia de Rael sigue su curso sin ninguna otra referencia a dicho personaje, dejándonos la impresión de que esa historia funciona más que como parte de la trama, como un excedente en la economía del texto que da cuenta de que "la realidad no cabe en un libro".

Un análisis de las tapas nos lleva a esta misma conclusión. La tapa de la primera edición del libro (Imagen 16, p. 290), publicada por Labortexto editorial, es la foto de un niño parado sobre la cornisa de un techo de chapa, detrás del cual se ven a lo alto otras casillas de construcción precaria con techos del mismo material. El niño tiene los brazos abiertos y las piernas un poco separadas, como si estuviera crucificado, tiene el torso al aire y lleva puestas solamente unas bermudas y una gorra y con su mano derecha sostiene un revólver. El fondo de la foto es en blanco y negro, pero la parte del cuerpo del niño está coloreada de un rojo que coincide con el color de la tipografía del título del libro. Los ojos del pequeño, por otro lado, están tachados con negro, de la misma manera que se tapan los ojos en los periódicos para no identificar al individuo. Llama la atención, como señala Leila Lehnen, que no haya juego entre la tapa y el relato, dado que al fin y al cabo "the novel's plot does not focus on youth violence, as suggested by the cover's imagery" (Lehnen, 2013, p. 137). Esta distorsión se repite en la tapa de la segunda novela de este escritor, Manual prático do ódio (Imagen 16, p. 290), que también muestra a un niño negro ya no con los ojos tapados, sino con nombre y apellido especificado en los créditos, ${ }^{3}$ y con dos alas de plumas que surgen de su espalda. Detrás suyo, nuevamente, se alzan una serie de construcciones precarias con techos de chapa a la vista y cables colgando, que no llegan a distinguirse del todo ya que parece estar anocheciendo. La novela, de todos modos, nada tiene que ver con la violencia infantil, sino que se centra en el planeamiento y la ejecución de un robo a un banco por parte de un grupo de amigos que viven en el mismo barrio, Capão Redondo. El montaje entre las tapas y el interior de cada texto deja un espacio vacío, indeterminado, que evidencia una falta de edición de esa "realidad" que se pretende "adaptar".

Manual prático do ódio también da a entender esta dificultad de hablar sobre esa "realidad". Según el título de la obra, lo que se leerá es un "manual práctico", una explicación, una serie de instrucciones simples y aplicables (prácticas) para comprender el odio, pero irónicamente se

\footnotetext{
3 "O autor e a editora agradecem a Rodnei Rodrigo Silva Borronco, o menino fotografado na capa".
} 
trata de un complejo entramado de relatos que le escapan a cualquier tipo de reduccionismo. Esta dificultad de "adaptar" esa "realidad" se percibe también en la forma misma de narrar, principalmente por la desorientadora puntuación cargada de comas y con pocos puntos, como expresando una dificultad por cerrar las ideas y, al mismo tiempo, expresando el ahogo de lo relatado al dejar sin aire al lector. El libro, por ejemplo, abre de esta manera:

Abriu os olhos rapidamente, afastou a coberta e levantou a cabeça, olhou fixamente e não a reconheceu, desviou o olhar para toda a casa e finalmente se situou, estava na casa de Rita em São Mateus, tocou o pingente que trazia na corrente e fez uma curta oração, olhou para o relógio e deduziu o horário que Anísio, o marido da Rita, chegaria, resolveu se arrumar apressadamente, foi ao banheiro, lavou o rosto, pegou a carteira e a pistola em cima do sofá e saiu (Ferréz, 2003, p. 13).

Se trata de un párrafo sin un solo punto seguido que en la edición de la novela ocupa ocho líneas. Y cada párrafo que sigue a este, algunos incluso el doble de extensos, tampoco presenta pausas más allá de las comas. El libro enseña la historia no de una manera didáctica, ${ }^{4}$ como lo haría en un "manual práctico", sino de una manera entrecortada, evidenciando la dificultad de explicar el odio.

El propio trabajo en relación con el vocabulario del libro también nos presenta una idea respecto a lo intraducible de cierta sonoridad y significados propios de ese territorio. Este autor, a diferencia de otros novelistas de las periferias de São Paulo como Alessandro Buzo o Sacolinha, no se preocupa por marcar entre comillas las jergas ni por explicarlas con un paréntesis o glosario. Si bien en general sus libros mantienen cierto lenguaje neutro, hay momentos (sobre todo los diálogos) que desbordan de jergas y frases crípticas y que pueden resultar incomprensibles para lectores ajenos a ese universo territorial y generacional:

- Régis, tem a moral de fazer um cavalo?

\footnotetext{
${ }^{4}$ El libro presenta, de todos modos, algunos momentos que, como afirma Paulo Tonani do Patrocínio, se pueden considerar didácticos en tanto pretenderían transmitir un mensaje de modo directo al público lector favelado, en sintonía con el quinto elemento del hip hop. "O estatuto literário passa a receber um invólucro disciplinador, através da escrita o autor enumera de forma clara e objetiva qual a postura social condizente com a imagem de sujeito periférico que espera formar no ato de leitura" (Patrocínio, 2013, p. 167).
} 
- Vai pra onde, Lúcio?

- Acho que vou colar lá no bar do Neco, tem como me levá?

- Tem sim, vamo aí.

- Falô, tru, a gente se tromba.

- Firmeza total.

El lenguaje empleado para narrar presenta ciertos espacios recónditos, fuera de control (Reyes, 2013, p. 151), espacios silenciados por la gramática del portugués padrón que no cualquier lector puede comprender.

La primera novela de Ferréz, por su parte, paralelamente al trabajo con las fotografías en su edición original, presenta indicios claros de una búsqueda de relatos para un real no editado. Sin ir más lejos, Rael, el nombre del personaje principal, es un anagrama de la palabra "real" (Penna, 2011, p. 291). Y cada uno de los textos escritos por raperos que dan inicio a las partes del libro (cinco en total) profundiza esta búsqueda:

[...] pondo os pés no chão, é bruta a nossa realidade [...]. Você já cresce no meio do veneno e chega uma hora em que o desespero é total. Vem a depressão pesada e, se não houver apoio, o maluco fica atacado, injuriado, pega uma arma e vira rápido um suicida. Condenado, arruma várias tretas, troca tiro, mata, o clima pesa, uma bomba pra você já foi programada, entende? É como uma cilada (Ferréz, 2000, p. 133-134)

Capão pecado busca, sin dudas, ahondar en ese "poner los pies en el suelo" y lo hace por medio de la dilatación de momentos íntimos o familiares de cada uno de los personajes que participan de la historia relatada. Frente a la reiterada presencia del acto violento en los discursos de los medios de comunicación tratados como un acto banal provocando así un sentimiento de miedo e impotencia en los espectadores (Martín-Barbero, 2003), los relatos de Ferréz buscan explorar las causas y los pensamientos, desnaturalizando el acto en sí. ${ }^{5}$ El ejemplo más claro en este sentido se puede percibir en la construcción de Burgos, uno de los personajes más temibles de la novela, pero que

\footnotetext{
${ }^{5}$ Se trata del mismo mecanismo que señala Ary Pimentel respecto de la fotografía de Bira Carvalho, artista formado por la Escola de Fotógrafos Populares y habitante de la Favela da Maré: "Não existe aqui a necessidade de documentar a realidade com planos abertos, de modo a mostrar a vida típica do homem nesse meio particular. O primeiríssimo plano é por demais eloquente. Os detalhes que levam o leitor da foto a povoar os quatro cantos da imagem de realidades que the foram sonegadas, têm por objetivo pôr em relevo um aspecto que a fotografia compartilha com outras artes: a reivindicação da atuação cúmplice e colaborativa do receptor" (Pimentel, 2014, p. 59).
} 
paralelamente a todas las crueldades que sobre él se cuentan nos enteramos, también, del sufrimiento que le genera tener un padre alcohólico dominado por la fe en la iglesia. De todos modos, la intimidad de los personajes en Capão pecado no está tan profundamente desarrollada como en la segunda novela de Ferréz.

Los personajes de Manual prático do ótico están particularmente trabajados: los "malos" en este libro no son completamente malos, todos tienen una rutina que los humaniza (la mayor parte de los fragmentos, por ejemplo, inicia con el despertar del personaje, es decir que siempre el enfoque es íntimo y afectivo), una historia de amor o algún tipo de vínculo amoroso y alguna cicatriz que se propone como causa del odio actual. Celso Capeta, por ejemplo, al comienzo es presentado así: "Nem na hora de assistir um filme ele se diverte, pensamento 100 por cento concentrado em maldade, não é à toa que lhe deram ainda criança o apelido de Celso Capeta" (Ferréz, 2003, p. 26). Pero a medida que avanza la novela va adquiriendo otros niveles de complejidad, ligados a una personalidad con un criterio estético, con sentimientos y nostalgias.

Celso Capeta gostava muito de caminhar, e pela manhã geralmente estava sozinho, não sabia explicar os sentimentos que apareciam de vez em quando, pois lhe batia uma vontade de ver rosas, notar os jardins, às vezes parava em frente a casas nas quais o jardim sempre fora bem cuidado, de uma certa forma a bondade do ser humano se acendia dentro dele, um nome sempre lhe vinha à mente, Márcia, um rosto que sempre lhe vinha aos olhos (Ferréz, 2003, p. 18).

También podemos encontrar igual nivel de complejidad en la historia de Régis, un personaje que evidencia una gran cantidad de matices (con todos los personajes podríamos pensar este mismo ejercicio). En primer lugar, se trata del personaje que abre y cierra el libro, y en esos dos extremos podemos ver por un lado el machismo y la violencia, y la ternura infantil por el otro. Se trata también de un personaje a quien le gusta caminar y que tiene una particular afinidad con los niños. En su caso también tenemos una situación propulsora del odio, vinculada al igual que con Celso desde la diferencia de clase:

A patroa da mãe de Régis lhe disse uma coisa que ficou com ele esse tempo todo, e ele guarda como o começo de sua revolta, como o começo de todo o ódio que nutria por quem tinha o que ele sempre quis ter, dinheiro. Um dia, durante uma conversa 
entre a patroa e sua mãe, a patroa perguntou de que bairro eles eram, sua mãe disse o nome do bairro, a patroa passou a mão na cabeça do pequeno e disse: - Então é esse pivete que um dia vai crescer e vir roubar minha casa? (Ferréz, 2003, p. 44)

El libro se preocupa, en este sentido, por cuidar especialmente la complejidad de los personajes $y$, a su vez, por presentar sus entornos de una manera muy precisa y detallada: el despertarse por la luz que entra por la grieta de los techos, los saltos dentro del auto por los pozos de las calles, el no poder concentrarse en la lectura por la música a todo volumen que escuchan los vecinos, el desmoronamiento de una casa narrado puertas adentro, el gusto de la leche pasada y el tacto del pan endurecido. "Estava muito frio naquela sexta-feira, Lúcio Fé odiava morar em barraco de madeira, o vento gelado entrava pelas frestas, quando estava calor as telhas esquentavam todo o barraco, quando chovia as goteiras eram a atração" (Ferréz, 2003, p. 143).

Los acontecimientos de los libros de Ferréz se acompañan de una instancia afectiva que consiste en dar cuenta de la vida privada o el pasado de los personajes, tal y como pudimos percibir en las citas anteriores. Este mecanismo que narra a los personajes y sus entornos "con lupa" parecería presentarse, a primera vista, como un "efecto de lo real" en el sentido barthesiano de una descripción detallada para aumentar la verosimilitud del texto ficcional. De todos modos, estas obras van más allá de la categoría de realismo, dado que exploran un estatuto inestable de lo real, precisamente porque la realidad se ha vuelto inverosímil. En este sentido cabe pensar que la estética detallística de Ferréz se asocia a la "irrupción intempestiva" que produce la imagen no editada, en palabras de Moriconi, efecto que suspende cualquier tipo de lectura en clave moralista, llevando al discurso hacia el plano de la ética. ${ }^{6}$ Se trata de un efecto que tiene que ver directamente con lo que plantea Beatriz Jaguaribe en tanto "choque de lo real":

Entendo o "choque do real" como um momento de intensificação catártica onde uma situação extrema seja de violência, terror, pobreza ou paixão é aguçada de forma tão verossímil que o

\footnotetext{
6 “Grosso modo, se poderia pensar a moral como um conjunto de valores e regras de ação propostos ao indivíduo de fora, por meio de parelhos prescriptivos diversos, como a família, as instituições educativas, as Igrejas etc. (Foucault, 1998). Já a ética diz respeito as opções internas que o indivíduo faz tentando não se sujeitar estritamente a esses sistemas” (Klinger, 2007, p. 56-57).
} 
leitor/espectador é tomado pela ficcionalidade e suspende seu julgamento. Vale enfatizar que este efeito catártico é forjado como os elementos do cotidiano. Não são episódios apocalípticos ou catastróficos que propiciam o "choque do real" [...] Para que o "real" apresentado choque é preciso que ele seja convincente e diverso do vocabulário e das imagens sensacionalistas usualmente exibidas nas mídias que saciam os anseios do grande público pelo "pão e circo" [...] Não se trata da nostalgia por um real alheio aos meios de comunicação, mas de uma apreensão das contradições, desejos e dúvidas de personagens e agentes diante do mundo fabricado (Jaguaribe, 2007, p. 107, el énfasis es mío).

Lo "real" vinculado a una situación de extrema cotidianeidad es presentado, en este sentido, parte por parte, como un "manual práctico", provocando en quien lo lee o mira un entendimiento de aquello que, desde otro punto de vista, o ignoraría o juzgaría. La escritura de Ferréz le plantea al lector alejarse de una mirada trascendente $y$, en este sentido, moralista, que suelen establecer los discursos que hablan sobre los delincuentes partiendo desde la idea del "mal" supuesto de que siempre son condenables, y lo lleva hacia una mirada inmanente, mostrando "lo bueno" y "lo malo" ligado a la cotidianeidad de dichos sujetos. "O autor nunca matou alguém por dinheiro mas sabe entender o que isso significa - do ponto de vista do assassino", dice en la contratapa del libro y su libro se ocupa de esa significación. La gran conmoción que causan en este sentido los textos de Ferréz se liga directamente a llevar al lector ajeno al mundo del crimen a alejarse de los juicios que sobre éste hacen pesar los medios ("discursos del consenso", como los denomina Rancière) y lo enfrenta a la incómoda sensación de identificación o simpatía por estos personajes, esto es, a un plano ético.

El trabajo alrededor de los personajes secundarios es central en este sentido. Como bien señala Alejandro Reyes (2013, p. 208), las novelas de Ferréz les dedican una especial atención. En Manual prático do ódio, por ejemplo, además de los personajes principales - los compañeros de crimen Régis, Neguinho da Mancha na Mão, Lúcio Fé, Celso Capera, Aninha y Mágico - y los otros malandros, policías y pés-de-pato (justicieros) involucrados directamente en el mundo del crimen y de la violencia, hay muchos otros que no forman parte del mundo del crimen. Pero la presencia de estos personajes no tiene que ver con ofrecer al lector elementos referenciales, sino que, como afirma Alejandro Reyes, 
funcionan "como parte indissociável da paisagem humana que compõe o universo periférico" (Reyes, 2013, p. 127):

A presença dessas personagens no romance não tem o efeito de mostrar o quanto são distantes os mundos do trabalhador e do malandro, mas, ao contrário, o quanto eles se assemelham na sua dimensão humana. Ao mesmo tempo, eles mostram a fragilidade das fronteiras entre um e outro e a dificuldade - "heroicidade"? de resistir às tentações do crime e do tráfico perante a brutalidade de um sistema que violenta e fecha todas as portas (Reyes, 2013, p. 127).

Las narraciones de Ferréz operan sobre una necesidad vital de transmitir experiencias y formas de vida que desorienten al lector en cuanto a su moral, impidiendo que las historias contadas queden reducidas a una mera valorización.

Pero, qué idea de ficción se destaca en estos textos excedidos por lo real?

Este real excesivo que explora Ferréz, ese "real no editado" en términos de Moriconi, es un real que reparte lo sensible de tal modo que modifica el horizonte de lo que es dado ver y sentir sobre las favelas y sus habitantes $\mathrm{y}$, en este sentido, se asocia a la idea de "ficción" desarrollada por Rancière, que no tiene que ver con una idea de ficción como opuesta a realidad, sino con las coordenadas de representación:

La ficción no es la creación de un mundo imaginario opuesto al mundo real. Es el trabajo que produce disenso, que cambia los modos de presentación sensible y las formas de enunciación al cambiar los marcos, las escalas o los ritmos, al construir relaciones nuevas entre la apariencia y la realidad, lo singular y lo común, lo visible y su significación. Este trabajo cambia las coordenadas de lo representable; cambia nuestra percepción de los acontecimientos sensibles, nuestra manera de relacionarlos con sujetos, la manera en la que nuestro mundo es poblado de acontecimientos y figuras (Rancière, 2008, p. 67).

La producción de Ferréz, como vimos, no se define a partir de la reproducción documental de un "mundo real" en formato escrito, sino que son ficciones entendidas como operaciones sobre la perspectiva de lo sensible. Las coordenadas de lo representable que ofrecen sus textos, al tiempo que afirman un punto de vista muy claro - vinculado con "o ponto de vista do assassino" -, presentan también zonas difusas, puntos de fuga y excesos, que se perciben a partir del montaje dislocado de lo 
icónico y lo verbal, del ritmo intempestivo, de un lenguaje fuera de control, de una dimensión del territorio y de los personajes afectiva y terrible al mismo tiempo, excesos que muestran el más allá de la palabra y de los juicios de valor.

\section{Referências}

BAUDRILLARD, Jean (2012/1978). Cultura y simulacro. Barcelona: Kairós.

BEAL, Sophia (2013). Brazil under construction. Fiction and public works. New York: Palgrave Macmillan.

BINHO (1997). Postesia. Poesía nos postes. São Paulo: Ed. del autor.

HOLLANDA, Heloísa Buarque de (2011). La literatura más allá de la marginalidad. In: FERRÉZ. Manual práctico del odio. Buenos Aires: Corregidor.

BUZO, Alessandro (2000). O trem - Contestando a versão oficial. São Paulo: ed. del autor.

DEBORD, Guy (1967/2008). La sociedad del espectáculo. Buenos Aires: La Marca.

FERRÉZ (2003). Manual prático do ódio. Rio de Janeiro: Objetiva.

FERRÉZ (2000). Capão pecado. São Paulo, Labor Texto Editorial.

JAGUARIBE, Beatriz (2007). O choque do real: estética, mídia e cultura. Rio de Janeiro: Rocco.

KLINGER, Diana (2007). Escritas de si, escritas do outro. O retorno do autor e a virada etnográfica. Rio de Janeiro: 7Letras.

LEHEN, Leila (2013). Citizenship and crisis in contemporary Brazilian literature. New York: Palgrave Macmillan.

LINS, Paulo (2002). Cidade de Deus. Rio de Janeiro: Companhia da Letras.

MARTÍN-BARBERO, Jesús (1998/1987). De los medios a las mediaciones. Bogotá: Convenio Andrés Bello.

MARTÍN-BARBERO, Jesús (2003). Los laberintos urbanos del miedo. Journal: Universitas Humanística, Bogotá, v. 56, n. 56, p. 69-79.

MORICONI, Ítalo (2006). Circuitos contemporâneos do literário (indicações de pesquisa). Gragoatá, Niterói, v. 11, n. 20, p. 147-163.

NASCIMENTO, Érica Peçanha do (2009). Vozes marginais na literatura. Rio de Janeiro: Aeroplano. 
PIMENTEL, Ary (2014). Selfie da periferia: pensando a autorrepresentação através da Literatura Marginal e da fotografia de Bira Carvalho. Aletria, v. 24, n. 2, p. 49-62.

RANCIÈRE, Jacques (2008). El espectador emancipado. Buenos Aires: Manantial.

REYES, Alejandro (2013). Vozes dos porões. A literatura periférica/marginal do Brasil. Rio de Janeiro: Aeroplano.

SCHØLLHAMMER, Karl E. (2009). Ficção brasileira contemporânea. Rio de Janeiro: Civilização Brasileira.

SÜSSEKIND, Flora (2005). Desterritorialização e forma literária. Literatura brasileira contemporânea e experiência urbana. Literatura e Sociedade, São Paulo, n. 8 , p. $60-81$.

TENNINA, Lucía (2013). Voces desde el margen. Literatura y favela. Seis ensayos sobre Manual Práctico del Odio. Buenos Aires: Edefyl.

VAZ, Sérgio; MUCCIOLO, Adriane (1988). Subindo a ladeira mora a noite. São Paulo: ed. del autor.

VAZ, Sérgio (1991). A margen do vento. São Paulo: ed. del autor.

ZIZEK, Slavoj (2005 [2002]). Bienvenidos al desierto de lo real. Madrid: Akal.

Recebido em fevereiro de 2016.

Aprovado em junho de 2016.

\section{resumo/abstract/resumen}

\section{Ferréz: além do documental}

\section{Lucía Tennina}

Este artigo visa pensar o lugar central da produção do Ferréz entre as produções da literatura brasileira atual a partir da contemporaneidade de seus interrogantes. Sustentamos que os seus dois primeiros romances Capão pecado (2000) y Manual prático do ódio (2003) levam a cabo um processo de desestabilização e reatualização da distinção entre ficção e não ficção, por um lado, e uma proposta singular do estatuto do real, por outro.

Palavras-chave: estatuto do real, favela, literatura marginal, Ferréz 


\section{Ferréz: besides the documentary}

\section{Lucía Tennina}

This article intends to reflect on the central place of Ferréz's production in the panorama of contemporary Brazilian literature inquiring into the contemporaneity of the questions it poses. We propose that his first two novels Capão pecado (2000) and Manual prático do ódio (2003) carry out a process of destabilization and renewal of the distinction between fiction and non-fiction, on the one hand, and a singular proposal of the status of the real, on the other.

Keywords: status of the real, favela, marginal literature, Ferréz.

\section{Ferréz: más allá del documentalismo}

\section{Lucía Tennina}

Este artículo apunta a pensar el lugar central que ocupa la producción de Ferréz entre las producciones de la literatura brasileña del presente a partir de la contemporaneidad de sus interrogantes. Sostenemos que en sus dos primeras novelas, Capão pecado (2000) y Manual prático do ódio (2003) lleva a cabo un proceso de desestabilización y reactualización de la distinción entre ficción y no ficción, por un lado, y una propuesta singular del estatuto de lo real, por otro.

Palabras clave: estatuto de lo real, favela, literatura marginal, Ferréz 